\title{
ASSESSMENT OF SAFETY OF PAIN CONTROL BY NON-OPIOID OVER-THE-COUNTER MEDICATIONS
}

\author{
KATARZYNA KARŁOWICZ-BODALSKA ${ }^{1 *}$, ERNEST KUCHAR ${ }^{2}$, \\ KRYSTYNA GŁOWACKA ${ }^{3}$ and ANNA WIELA-HOJENSSKA ${ }^{3}$ \\ ${ }^{1}$ Department of Industrial Pharmacy, Wroclaw Medical University, \\ Faculty of Pharmacy, Wroclaw, Poland \\ ${ }^{2}$ Department of Pediatrics with Clinical Assessment Unit, \\ Medical University of Warsaw, Poland \\ ${ }^{3}$ Department of Clinical Pharmacology, Wroclaw Medical University, \\ Faculty of Pharmacy, Wroclaw, Poland
}

\begin{abstract}
Non-opioid analgesics are among the most popular over the counter (OTC) drugs in Poland. One of the main reasons for the increasing risk of the drugs' side effects is their accessibility and popularization of selfmedication among patients. This study analyzed and assessed the safety of selected non-opioid analgesics issued without a doctor's prescription (i.e. OTC) based on original survey, adverse effects reports from the Regional Center for Monitoring of Adverse Drug Reactions in Wroclaw, drug manufacturers, and the European EudraVigilance database. The research showed that the most commonly used non-opioid OTC analgesics are ibuprofen, paracetamol, and acetylsalicylic acid. Pharmacotherapy using these substances entails a risk of adverse effects, which increases the number of painkillers used. Pain medications should be purchased at a pharmacy and their sale should be accompanied by a pharmacist's advice.
\end{abstract}

Keywords: non-opioid drugs, OTC, pain, safety of pharmacotherapy

Pain, which plays a warning role in the body, is the most common symptom in medicine. It has always been part of the human condition, and many people suffer because of it. According to the International Association for the study of Pain it is defined as "An unpleasant sensory and emotional experience associated with, or resembling that associated with, actual or potential tissue damage" and is felt when the intensity of the stimulus exceeds the subjective physiological limits of the body (1). Both acute and chronic pain is the cause of the use and often abuse of commonly available non-opioid analgesics. They are recommended for the treatment of inflammation of the skeletal and muscular system, in the case of post-traumatic pain, postoperative pain, headache, and cancer. They are also used in the treatment of infectious diseases with elevated temperatures and the treatment of dermatological diseases. However, it is not always remembered that their proper selection should take into account such factors as the pathomechanism of pain generation, its severity, location, duration, differentiation of the type of pain (acute, blunt, diffuse, seizure), accompanying symptoms, and, of course, the patient's age. It is important to assess patients individually in terms of their expected analgesic efficacy and adverse reaction profile, taking into account the pharmacodynamic and pharmacokinetic properties of drugs, the risk of their combination with each other, and with other therapeutic substances. The psychological, social, and even spiritual sphere of patients must not be forgotten either, as they also have an impact on their suffering (2-10).

Unfortunately, these aspects of pain therapy are often overlooked. Moreover, uncontrolled access to non-opioid analgesics, supported by their overoptimistic advertising and the expectation of immediate effectiveness, and therefore reaching for new preparations and exceeding the acceptable dose, may cause various dangerous consequences, especially in patients belonging to risk groups such as children, elderly people, dehydrated people, those

\footnotetext{
* Corresponding author: e-mail: katarzyna.karlowicz-bodalska@umed.wroc.pl
} 
with chronic diseases, and after organ transplants (11, 12). Often, these drugs are taken inconsistently with the recommendations, in too high doses, with no regard to e.g. a ceiling effect on non-steroidal antiinflammatory drugs (NSAIDs) or together with other preparations, which leads to undesirable interactions that may result in a significant reduction of the analgesic effect or toxic reactions. The indication for the use of NSAIDs is musculoskeletal pain of different etiologies, pain that is inflammatory and can be combined with opioids in case of pain that is difficult to treat. They are effective in all types of nociceptive pain (mechanical, inflammatory, visceral). Paracetamol (acetaminophen) is used in the treatment of somatic pain because it has no anti-inflammatory effect and metamizole in visceral pain because of its central spasmolytic effect. An additional analgesic effect is observed when NSAIDs are associated with paracetamol and/or metamizole, which, in the light of the available knowledge about its mechanism of action, cannot be classified as a non-steroidal antiinflammatory drug $(13,14)$. The characteristics of the mechanism of action and complications of non-opioid analgesics are presented in Table 1 (2, 5, 6, 15-38).

Table 1. Characteristics of selected non-opioid analgesics.

\begin{tabular}{|c|c|c|c|}
\hline Drugs & NSAIDs & Paracetamol & Metamizole \\
\hline $\begin{array}{l}\text { Mechanism } \\
\text { of action. }\end{array}$ & $\begin{array}{l}\text { Mechanism of action inhibition: } \\
\text { cyclooxygenase (COX) activity, } \\
\text { expression of inductive nitric } \\
\text { oxide synthase, activation of } \\
\text { NF-kappa B, the activity of P } \\
\text { substance; activation: lipoxin } \\
\text { system, supraspinal cholinergic } \\
\text { pathways, endogenous opiate } \\
\text { peptide system }\end{array}$ & $\begin{array}{l}\text { Inhibiting the central activity of } \\
\text { the COX-3 isoform, influencing } \\
\text { the central oxidoreductive } \\
\text { mechanism, increasing the } \\
\text { activity of the descending } \\
\text { antinociceptive pathway by } \\
\text { inhibiting serotonin reuptake, } \\
\text { potentiation of endogenous } \\
\text { cannabinoids (anandamide) in } \\
\text { the CNS (pain perception cen- } \\
\text { ters) and the pathways involved } \\
\text { in thermoregulation > through } \\
\text { agonistic effects on cannabinoid } \\
\text { receptors CB1 and vanilloid } \\
\text { TRPV1 }\end{array}$ & $\begin{array}{l}\text { Agonistic effects on } \mathrm{CB} 1 \text { and } \\
\mathrm{CB} 2 \text { receptors in the center of } \\
\text { and peripheral nervous system, } \\
\text { increase in the secretion of } \\
\text { endogenous opioid peptides, } \\
\text { inhibition of central and periph- } \\
\text { eral COX-1 and COX-2 isoform } \\
\text { activity, P-induced nociception, } \\
\text { adenosine reuptake }\end{array}$ \\
\hline Effects & $\begin{array}{l}\text { Analgesic, antipyretic, } \\
\text { anti-inflammatory }\end{array}$ & Analgesic, antipyretic & $\begin{array}{l}\text { Analgesic, antipyretic, } \\
\text { spasmolytic }\end{array}$ \\
\hline $\begin{array}{l}\text { Adverse } \\
\text { drug } \\
\text { reactions }\end{array}$ & $\begin{array}{l}\text { Gastrointestinal tract - gastroin- } \\
\text { testinal disorders, damage to the } \\
\text { gastric and duodenal mucosa, } \\
\text { perforation of the ulcer, } \\
\text { enteropathy with diarrhea, inhi- } \\
\text { bition of platelet aggregation - } \\
\text { prolonged bleeding time, an } \\
\text { asymptomatic increase of } \\
\text { aminotransferase activity (rarely } \\
\text { liver damage), coil-parietal } \\
\text { interstitial nephritis, impairment } \\
\text { of their function: hyperkalemia, } \\
\text { sodium and water retention, risk } \\
\text { of swelling, increase in blood } \\
\text { pressure, headaches and dizzi- } \\
\text { ness, increased risk of myocar- } \\
\text { dial infarction, heart failure, and } \\
\text { ischemic stroke, aspirin asthma, } \\
\text { increased risk of bronchospasm, } \\
\text { skin reactions - ossification, } \\
\text { itching, erythema, allergic reac- } \\
\text { tions, increased risk of miscar- } \\
\text { riage, the possibility of embry- } \\
\text { otoxic effects and teratogenic, } \\
\text { premature closure of the } \\
\text { Botallo's duct }\end{array}$ & $\begin{array}{l}\text { Allergic skin reactions - asphyx- } \\
\text { ia, erythema, redness, gastric } \\
\text { disorders, transient neutropenia, } \\
\text { anemia, thrombocytopenia } \\
\text { (rare), liver damage, kidney }\end{array}$ & $\begin{array}{l}\text { Allergic reactions (especially } \\
\text { cutaneous - urticaria, erythema, } \\
\text { exfoliating and inflammatory } \\
\text { lesions, rarely - laryngeal } \\
\text { edema, bronchospasm), hypoto- } \\
\text { nia, interstitial nephritis and } \\
\text { papillary necrosis (in chronic } \\
\text { use), hyponatremia, damage to } \\
\text { the gastrointestinal mucosa, } \\
\text { nausea, vomiting, diarrhea, liver } \\
\text { damage, arrhythmia, myelotoxi- } \\
\text { city, agranulocytosis. }\end{array}$ \\
\hline
\end{tabular}




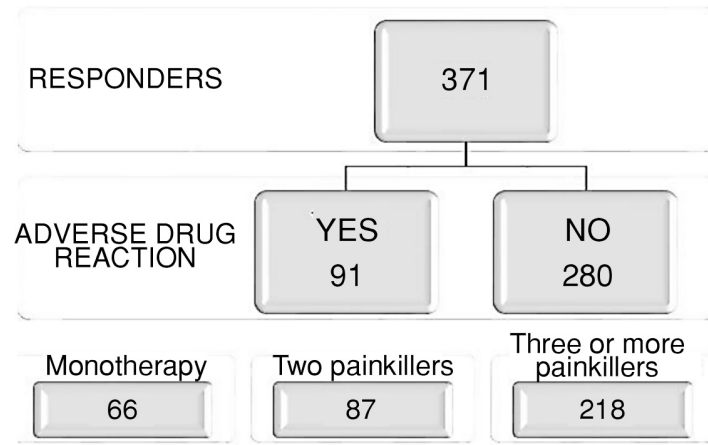

Figure 1. Characteristics of the study group in terms of non-opioid analgesics used and their consequences.

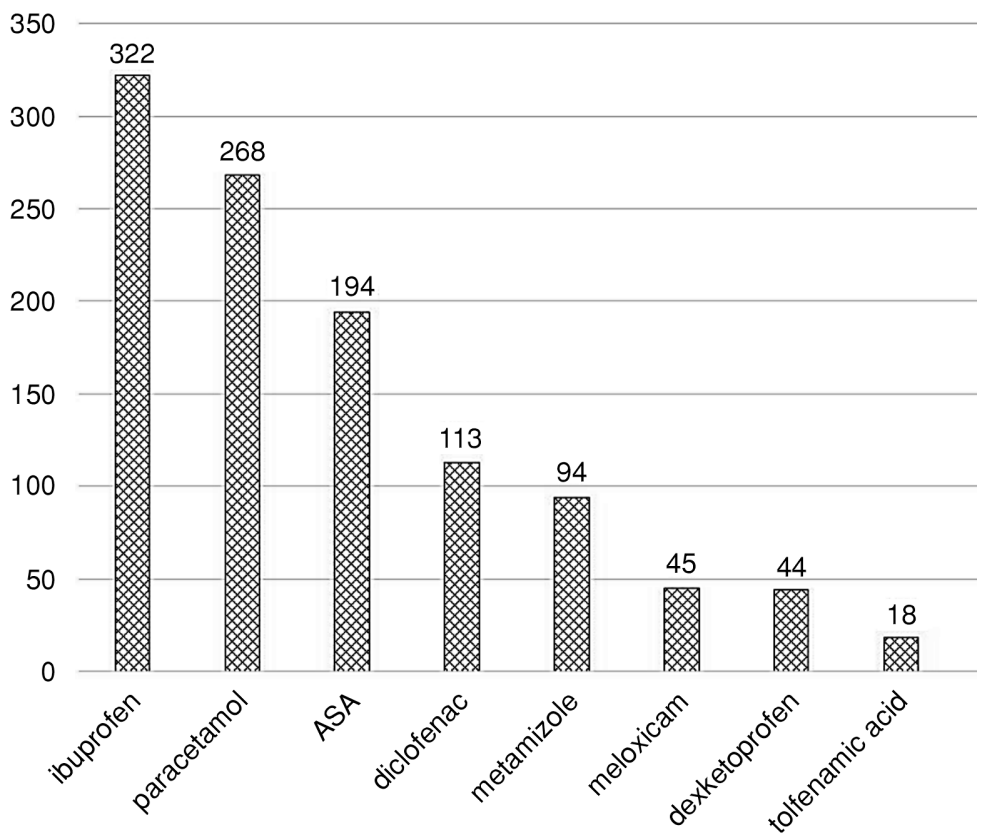

Figure 2. Type of non-opioid painkillers taken.

The aim of the study was the assessment of the safety of pain treatment by non-opioid over-thecounter painkillers.

\section{EXPERIMENTAL}

The research material consisted of data obtained from a questionnaire interview conducted with 371 respondents in both online and paper form. The survey was carried out in the period from February to May 2018 with the consent of the Bioethical Committee of the Medical University in Wroclaw (104/2018).

The research tool used was an original, validated, anonymous questionnaire, consisting of 20 ques- tions, which checked, among others, the respondents' knowledge of the OTC painkillers they were taking (NSAIDs, paracetamol, metamizole), the occurrence of pharmacotherapy complications, and the possibility of reporting them. The criterion for inclusion in the study was the use of painkillers available without a prescription.

The obtained answers from the original survey were analyzed statistically using Statistica (version 13.1 Stat Soft Inc.). Correlations between variables were checked using Pearson's chi-squared test. The values for which $\mathrm{p}<0.05$ were considered statistically significant.

Additionally, the observation material consisted of reports of undesirable effects of non-opioid 
analgesics from the Regional Monitoring Centre for Undesirable Drug Effects in Wrocław from January 2006 to June 2020, from their manufacturers: PPF Hasco-Lek S.A., US Pharmacia Sp. z o.o. (both from January 2008 to June 2020), and collected in the European database EudraVigilance (January 2019 to December 2019).

\section{RESULTS}

The study group consisted of 371 respondents, aged between 18 and 64, including 251 (67.7\%) women and $120(32.3 \%)$ men. Observations were made of $184(49.6 \%)$ students and $144(38.8 \%)$ working people, as well as $31(8.4 \%)$ retirees and $12(3.3 \%)$ pensioners. The survey was correctly filled in and 371 people reported the use of non-opioid analgesics available over the counter), 24 respondents did not take analgesics and these questionnaires were not included in the survey, and 91 people reported the occurrence of adverse effects of the applied therapy. Those data are presented in Figure 1.

This survey is subject to several limitations. The first is that the study area is narrowed to the territory of Poland. The second is the high percentage of responses from young people and therefore the age distribution was not normal.

Analysis of the type, frequency, number, and timing of OTC analgesics and their adverse effects

The intake of ibuprofen was reported by 322 $(86.8 \%)$ respondents, paracetamol 268 (72.2\%), acetylsalicylic acid (ASA) 194 (52.2\%), diclofenac
$113(30.5 \%)$ and metamizole 94 (25.3\%). A complete list of drugs is presented in Figure 2.

The most commonly taken non-opioid analgesics were ibuprofen, paracetamol, acetylsalicylic acid, diclofenac, and metamizole. 346 (93.3\%) respondents used them "temporarily in case of pain", most often directly after a meal (Figure 3).

Complications related to the treatment of pain killers with OTC accessibility were reported by 91 $(24.5 \%)$ respondents. They most often experienced disorders of the gastrointestinal tract; the main ailments in this group were heartburn in 42 (46.2\%), abdominal pain in $37(40.7 \%)$, diarrhea in 26 $(28.6 \%)$, and nausea and vomiting in $22(24.2 \%)$ subjects, also sensitization reactions in 17 (18.7\%) and bleeding in $3(3.3 \%)$ subjects. Single complaints included drowsiness, fainting, concentration problems, limb numbness, or headaches. The drugs related to adverse effects occurrence, as confirmed by statistical analysis, were ASA ( $p=0.0413)$, diclofenac $(\mathrm{p}<0.001)$, meloxicam $(\mathrm{p}<0.001)$ and dexketoprofen $(\mathrm{p}<0.001)$.

\section{Pain relief monotherapy}

Only one analgesic was reported to have been taken by 66 (17.8\%) people, including ibuprofen 39 $(59.1 \%)$ because of headache, menstrual pain, teeth, joints, spine, and cold. Less than once a month 22 $(5.9 \%)$ respondents used this drug, several times a month $13(3.5 \%)$ and several times a week $4(1.1 \%)$. Five respondents observed side effects, three had sensitization reactions, one had abdominal pain, heartburn, nausea, and vomiting with diarrhea, and another had abdominal pain, heartburn, nausea, and

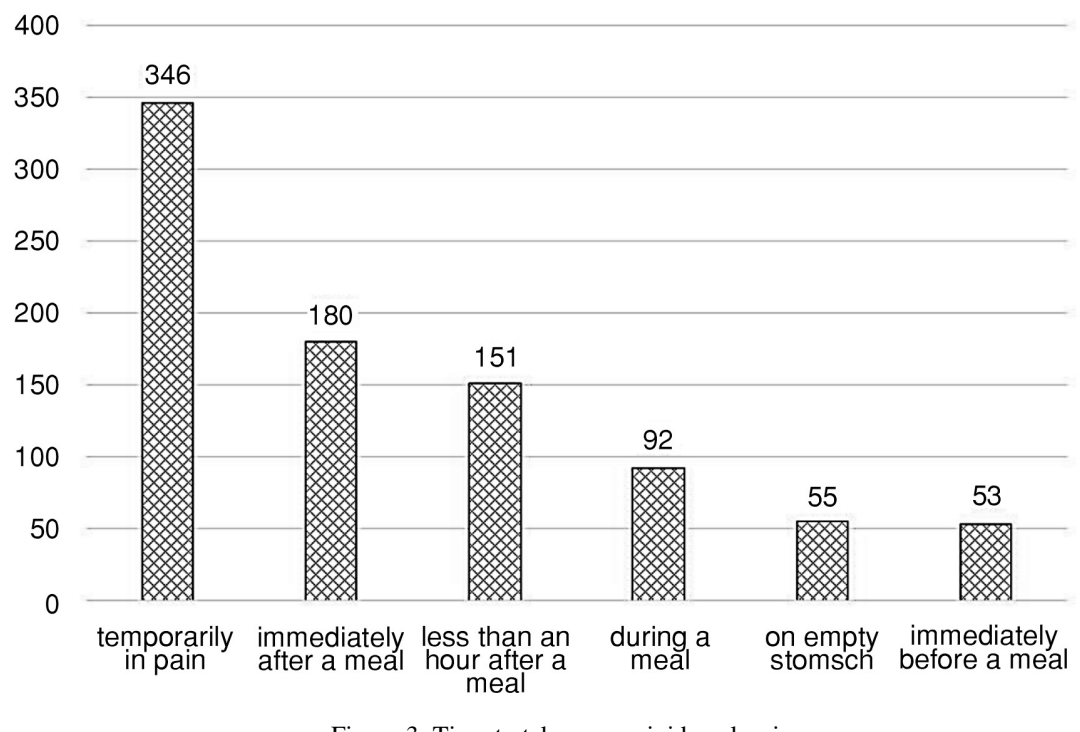

Figure 3. Time to take non-opioid analgesics. 
Table 2. Analysis of taking two non-opioid analgesics in total.

\begin{tabular}{|l|c|c|}
\hline \multicolumn{1}{|c|}{ Drugs } & Number of responders & Reason for use \\
\hline Ibuprofen + paracetamol & 52 & Headache, toothache, joint pain, cold \\
\hline Ibuprofen + ASA & 15 & Headache, menstrual pain, cold \\
\hline ASA + paracetamol & 6 & Headache, cold \\
\hline Ibuprofen + dexketoprofen & 3 & Headache, menstrual pain, cold \\
\hline Paracetamol + diclofenac & 2 & Headache, toothache, cold \\
\hline Paracetamol + metamizole & 2 & Headache, toothache \\
\hline Ibuprofen + metamizole & 2 & Menstrual pain \\
\hline Meloxicam + paracetamol & 1 & Joint pain \\
\hline Meloxicam + diclofenac & 1 & Headache, spinal pains, discopathy \\
\hline Meloxicam + dexketoprofen & 1 & \\
\hline
\end{tabular}

vomiting with a headache. They occurred after taking ibuprofen several times a month or several times a week but did not occur when the drug was used less than once a month. Only paracetamol therapy was reported by 15 (4.0\%) respondents, of which 10 less frequently than once a month, several times a month 4 respondents and several times a week 1 person. The causes were mainly headaches and menstrual pains. In two respondents, sensitization reactions, heartburn, reflux, and sensitive bowel syndrome occurred several times a month while taking the drug.

ASA monotherapy was used by $5(1.3 \%)$ subjects, of whom 4 used it less frequently than once a month and 1 person several times a month. The indications were cold, tooth, head, and joint pain. One respondent taking the drug less frequently than once a month indicated heartburn as a complication.

Neither metamizole used because of a tooth, head, and menstrual pain less frequently than once a month by 3 women surveyed, nor diclofenac, taken by two women because of joint pain, one every day, the other less frequently than once a month, caused side effects. However, out of two respondents using only meloxicam, one using it daily for joint pain reported abdominal pain as a complication, while the other one, taking the drug several times a week because of knee pain, did not report any complications.

\section{Use of two painkillers}

Simultaneous use of two non-opioid analgesics was reported by $85(22.9 \%)$ respondents. In this group, $52(61.2 \%)$ people combined paracetamol and ibuprofen due to headache (43), menstrual pain (24), teeth (24), and joints (10). Six had abdominal pain, vomiting, nausea, heartburn, and diarrhea. A 22-year-old woman experienced fainting, sleepiness, and concentration problems. The use of ibuprofen and ASA was reported by 15 (17.6\%) respondents, the cause being headaches (12), menstrual pains (6), and a cold (3). Unwanted actions were observed in a man - heartburn, nausea, vomiting, and numbness of extremities - and a woman abdominal pain, nausea, vomiting, and gastrointestinal bleeding. Ibuprofen was associated with dexketoprofen by three people in headache, toothache, menstrual pains, and colds. Complications were reported by one woman in the form of abdominal pain and heartburn. In the remaining cases, therapy with two drugs did not cause any side effects. The analysis of the combination of analgesics and the reasons for their use is presented in Table 2.

Ibuprofen was most often combined with other analgesics. Out of $72(19.4 \%)$ respondents using this combination, 9 (12.5\%) experienced side effects. Paracetamol with other drugs was used by 63 (16.9\%) respondents, among whom 6 (9.5\%) observed complications. Integrated acetylsalicylic acid therapy with another drug was used by 21 respondents, two of whom $(9.5 \%)$ experienced side effects.

\section{Use of three or more painkillers}

The use of 3 drugs was reported by 218 (58.8\%) respondents, among them 158 women and 60 men. Ibuprofen was used in this way by 208 (95.4\%) people; 66 (31.7\%) of this group experienced side effects. Paracetamol and other analgesics were used by 191 (87.6\%) respondents; 62 (32.5\%) had complications. Acetylsalicylic acid and other analgesics were used by 169 (77.5\%) respondents; 
$56(33.1 \%)$ observed side effects. Headache (191), menstrual pain (96), toothache (76), and joint pain (75) were the cause of polytherapy. During the therapy with three or more analgesics, $73(33.5 \%)$ persons reported side effects. The most commonly observed were heartburn (34), abdominal pain (29), diarrhea (23), nausea and vomiting (16), as well as sensitization reactions (11), and single cases of sleepiness. One of the respondents gave a hemorrhage as a complication of treatment.

Most of them did not combine OTC pain killers and those prescribed by the physician, while only 48 (12.9\%) used them together due to headaches, menstrual pain, teeth or joint pain, and colds.

Verifying patients' knowledge of the possibility of reporting adverse drug reactions

Among the respondents, $21(5.6 \%)$ were not aware of having such a legal right, while 54 (14.6\%) informed the doctor about the occurrence of drug complications, $13(3.5 \%)$ gave the data to the pharmacist, $8(2.2 \%)$ to the nurse, and $5(1.3 \%)$ to the dentist. Only two of the respondents used the form available on the website of the Office for Registration of Medicinal Products, Medical Devices and Biocidal Products.

Analysis concerning the place of purchasing nonopioid analgesics and sources of information about the drug

$358(96.5 \%)$ people indicated a pharmacy as their main place of purchase for analysts, but only $175(47.1 \%)$ of the respondents received the phar- macist's advice, while in as many as 182 (49.1\%) cases it was not given. Fourteen $(3.8 \%)$ people did not remember this fact. The pharmacist most often provided information on the dosage, time of taking the drug, use before or during a meal, interaction with other drugs, and side effects.

The majority of 297 (80.1\%) respondents indicated the drug leaflet as the primary source of knowledge about drugs, followed by 239 (64.4\%) mentioning the Internet, $218(58.8 \%)$ the doctor, and $175(47.2 \%)$ the pharmacist.

Analysis of understanding of the contents of package leaflets, use of drugs according to the information contained therein

Based on their own observations, it was found that 361 respondents $(97.3 \%)$ read the leaflets, 283 $(76.3 \%)$ understood their content, while for 100 $(27.7 \%)$ not all the information contained therein was comprehensible. $342(92.2 \%)$ respondents used the medications according to their indications, but some of them missed doses, decreased or increased them, interrupted their therapy, or took the medicine when time allowed (Figure 4).

Analysis of adverse effects of non-opioid analgesics reported to the Regional Monitoring Centre for Undesirable Drug Effects in Wrocław, to the responsible entities of PPF Hasco-Lek S.A. and US Pharmacia, and the European EudraVigilance database

Between January 2006 and 2020, 80 reports of adverse effects of analgesics were submitted to the

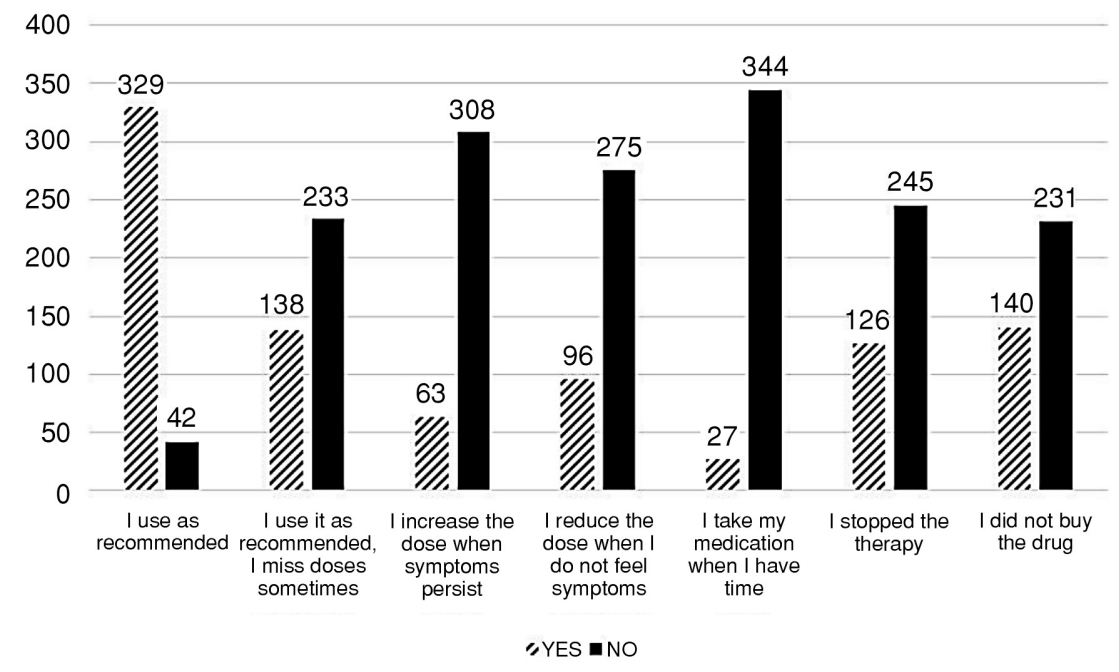

Figure 4. Analysis of the use of non-opioid analgesics as described in the drug leaflets. 
Table 3. Analysis of the frequency of reports to the European EudraVigilance database of adverse effects of non-opioid pain killers by age of patients.

\begin{tabular}{|c|c|c|c|c|c|}
\hline Age (years) & Ibuprofen & Paracetamol & ASA & Metamizole & Diclofenac \\
\hline $0-17$ & 7591 & 8199 & 2117 & 752 & 1219 \\
\hline $18-64$ & 21397 & 31484 & 25129 & 4788 & 19907 \\
\hline $65-85$ & 6265 & 8170 & 38878 & 2578 & 11267 \\
\hline$>85$ & 6265 & 1766 & 9330 & 450 & 1885 \\
\hline Not specified & 980 & 11821 & 10555 & 1596 & 7055 \\
\hline total & 43074 & 61440 & 86009 & 10164 & 41333 \\
\hline
\end{tabular}

Table 4. Analysis of reporting rates to the European EudraVigilance database of adverse effects of non-opioid analgesics by gender of patients.

\begin{tabular}{|c|c|c|c|c|c|}
\hline Sex & Ibuprofen & Paracetamol & ASA & Metamizole & Diclofenac \\
\hline Women & 23565 & 33747 & 35979 & 5997 & 22922 \\
\hline Men & 16879 & 20077 & 44969 & 3794 & 16715 \\
\hline Not specified & 2630 & 7616 & 5061 & 373 & 1696 \\
\hline Total & 43074 & 61440 & 86009 & 10164 & 41333 \\
\hline
\end{tabular}

Regional Centre for Monitoring of Adverse Drug Reactions in Wrocław, 27 were related to the use of ASA, 12 to metamizole, 6 to ibuprofen, 4 to paracetamol, and 2 to ketoprofen. Several cases were related to the occurrence of adverse reactions after taking two or more analgesics, both of the nature of OTC availability and the doctor's prescription. Patients often took the drugs together or at short intervals of time, so it is difficult to clearly state which one was responsible for causing the complications. However, a link has been established between the occurrence of symptoms such as skin complications, urticaria, erythema, and angioedema, and combined therapy with ASA and ketoprofen; ASA and diclofenac; ASA, paracetamol, diclofenac, and ketoprofen; ibuprofen and diclofenac; ASA, ketoprofen and azithromycin. We also reported a case of fainting and diarrhea after diclofenac and metamizole, as well as a pressure drop and consciousness disorder after 1 injection of ketoprofen $(100 \mathrm{mg})$ in a man also taking acetylsalicylic acid. This patient, after several days of continuing ASA therapy, also began to experience bronchospasmodic dyspnea. All reported cases of complications came from physicians and mainly concerned ASA, metamizole, ibuprofen, and paracetamol.

Responsible parties of PPF Hasco-Lek S.A. received 47 reports of adverse effects of OTC painkillers in the period of January 2008 - June 2020, while US Pharmacia Sp. z o.o. received 70 reports in the period of January 2013 - June 2020.
Of the above-mentioned drugs, only ibuprofen complications (37 cases) were recorded in both databases. These included mainly gastrointestinal disorders manifested by vomiting and bleeding and skin complications, erythematous changes, and angioedema. Among the 28 reports on paracetamol made available by US Pharmacia, there were skin lesions: urticaria, maculopapular rash, erythema, and itching. Two patients developed general weakness and malaise, one man had $3000 \mathrm{mg}$ of paracetamol hand and leg muscle paresis. Also, single cases of increased pressure, leukopenia, and anemia as well as impaired renal function with dark urine staining were reported. Eleven spontaneous reports from the database were found to be severe side effects. Four of them concerned skin lesions, four consecutive hepatotoxic effects due to paracetamol poisoning, one patient experienced an increase in alanine and aspartate aminotransferases, as well as clotting disorders and coagulopathy, and one patient felt sleepy after taking the drug. The fatal case involved a 60year-old man who, after an overdose of paracetamol, developed severe poisoning with liver and kidney damage. The US Pharmacia Sp. z o.o. database also contains seven cases from the literature, all of which were considered severe. Four were the result of paracetamol overdose, three were related to suicide attempts. One of the reports concerned a 53-year-old man who had a combination of drug and ethanol poisoning, developed metabolic acidosis with an anionic gap, lactate acidosis, acute respiratory fail- 
ure, acute renal failure, and rhabdomyolysis. Other cases from the literature have described typical complications for paracetamol therapy, such as liver damage or failure, non-allergic hypersensitivity to the drug together with exacerbation of asthma (coughing, dyspnea, respiratory failure), and skin reactions in the form of a fine-spotted hemorrhagic rash.

In the European EudraVigilance database, since the database was created to August 2020, for ibuprofen there were 43074 , for paracetamol 61 440, for ASA 86009 , for metamizole 10 164, and for diclofenac 41333 cases of their adverse effects recorded, as shown according to patients' age in Table 3 and gender in Table 4.

Most adverse effects of ibuprofen, paracetamol, metamizole, and diclofenac were observed in patients aged 18 to 64 years, mainly women. Only in the case of ASA did they affect primarily people whose age ranged from 65 to 85 years, mainly men. The most common adverse effects of non-opioid analgesics registered by EudraVigilance in 2019 are shown in Table 5.

\section{DISCUSSION AND CONCLUSION}

The OTC drug market in Poland is one of the best developed in Europe. As a result of their advertising, often showing only the benefits, as well as easy access, the consumption of these preparations maintains a high level. According to the CBOS research, independent use of OTC drugs takes third place (indicated by $21 \%$ of adults), after consulting the doctor and taking the prescribed medical products $(30 \%)$ and using so-called home remedies (29\%). Painkillers and anti-inflammatory drugs are most often used in this way, as the patient nowadays expects fast, effective, and cheap treatment, especially for pain $(39,40)$. The respondents were most likely to take ibuprofen ( $\mathrm{n}=322,86.8 \%)$, paracetamol $(\mathrm{n}=268,72.2 \%)$, ASA $(\mathrm{n}=194,52.3 \%)$, diclofenac $(\mathrm{n}=113,30.5 \%)$ and metamizole $(\mathrm{n}=$ 94, 25.3\%). The obtained results are consistent with the Polish observations of Kozłowski et al. and Koffeman et al. in the Netherlands, which confirmed patients' preferences for choosing non-opioid analgesics $(41,42)$. In the population at risk of gastroin-

Table 5. Analysis of the most common adverse effects of non-opioid analgesics registered by EudraVigilance in 2019.

\begin{tabular}{|c|c|c|c|c|c|}
\hline Adverse drug reactions & Ibuprofen & Paracetamol & ASA & Metamizole & Diclofenac \\
\hline Gastrointestinal disorders & 1529 & 1505 & 3222 & 291 & 859 \\
\hline $\begin{array}{l}\text { Skin and subcutaneous tissue } \\
\text { disorders }\end{array}$ & 1225 & 1696 & 868 & 402 & 1346 \\
\hline $\begin{array}{l}\text { General disorders and admini } \\
\text { stration site conditions }\end{array}$ & 1148 & 2189 & 1371 & 345 & 1161 \\
\hline Nervous system disorders & 668 & 1351 & 1507 & 211 & 460 \\
\hline $\begin{array}{l}\text { Respiratory, thoracic and } \\
\text { mediastinal disorders }\end{array}$ & 500 & 560 & 1116 & 175 & 302 \\
\hline Psychiatric disorders & 473 & 1105 & 388 & 105 & 184 \\
\hline Immune system disorders & 418 & 346 & 346 & 153 & 349 \\
\hline Renal and urinary disorders & 307 & 271 & 1065 & 52 & 215 \\
\hline Cardiac disorders & 207 & 306 & 624 & 69 & 152 \\
\hline $\begin{array}{l}\text { Blood and lymphatic system } \\
\text { disorders }\end{array}$ & 176 & 252 & 695 & 264 & 103 \\
\hline Hepatobiliary disorders & 160 & 876 & 174 & 51 & 69 \\
\hline Vascular disorders & 234 & 306 & 910 & 91 & 154 \\
\hline
\end{tabular}

Table 6. Comparison of the number of non-opioid analgesics and their adverse effects.

\begin{tabular}{|c|c|c|}
\hline Number of non-opioid painkillers used & Number of respondents & Number of adverse reactions \\
\hline 1 & 66 & 9 \\
\hline 2 & 85 & 9 \\
\hline 3 & 218 & 73 \\
\hline
\end{tabular}


testinal, cardiovascular, and renal diseases, predispositions according to Koffeman et al. were slightly different; $53 \%$ chose ASA, 29\% chose ibuprofen, $11 \%$ chose diclofenac and $8 \%$ chose naproxen. $18 \%$ of people took two or more drugs, and $33 \%$ for more than seven days (42). The results of a populationbased, non-interventional prospective study conducted by Regula et al. indicated yet another pattern of drug use - diclofenac, ketoprofen, ASA, ibuprofen, and nimesulide. They found, in contrast to the other studies, that monotherapy (57\%), and less frequently two (29\%), and three (10\%) drugs were used (43). As many as $218(58.8 \%)$ of our respondents combined three or more analgesics, 208 (95.4\%) chose ibuprofen as one of them, 66 (31.7\%) experienced therapy complications such as heartburn, abdominal pain, diarrhea, nausea, vomiting, allergic reactions, and sleepiness. Two painkillers were used by a total of $85(22.9 \%)$ people, including 52 (61.2\%) ibuprofen and paracetamol. 20 respondents reported combining several representatives of NSAIDs, which is undoubtedly a mistake and does not improve the effectiveness of treatment but increases the risk of damage to the upper gastrointestinal tract as well as liver and kidneys. Table 6 presents a comparative analysis of the number of non-opioid analgesics used and the complications caused by them.

As can be seen from the above summary, 91 people experienced side effects during treatment with OTC painkillers. Statistically significant relationships between the number of medicinal products used and the occurrence of complications were demonstrated. In assessing the safety profile of nonopioid analgesics, some authors have positively distinguished ibuprofen, which has recently gained a negative reputation for worsening the course of COVID-19 disease, but this has been denied by the World Health Organization and the European Medicines Agency $(44,45)$. In this study it was used in monotherapy by $39(59.1 \%)$ respondents; 5 of them observed adverse effects - sensitization reactions and gastrointestinal disorders. Throughout 13 and 8 years, respectively, the responsible entities PPF Hasco-Lek S.A. and US Pharmacia Sp. z o.o. received a total of 37 reports of its complications, which manifested as vomiting, gastrointestinal bleeding, skin lesions, mainly erythema and angioedema. Only 6 cases of complications were reported to the Regional Centre for Monitoring of Adverse Drug Reactions in Wroclaw in 2006-2020. However, in the European database EudraVigilance until August 2020, as many as 43074 adverse reactions were registered for ibuprofen. Most of them concerned people aged 18-64 years, especially women. Gastroenterological disorders dominated (1529). Another representative of the NSAIDs covered by its observations was ASA. Although in the questionnaire study there were practically no complications, 27 such instances were found in the database of the Regional Monitoring Centre for Undesirable Drug Effects in Wrocław. However, in the EudraVigilance collection only a month ago there were 86009 cases. They mainly concerned gastrointestinal disorders (3222) in elderly people (65-85 years old). The safety of ibuprofen, compared to paracetamol and ASA, was assessed in the PAIN study, which involved 8677 patients with acute pain. It was found that ibuprofen at a dose of $1200 \mathrm{mg} / \mathrm{d}$ was similar to paracetamol at a dose of $3000 \mathrm{mg} /$ day $(13.7 \%$ vs. $14.5 \%)$ in terms of the number of adverse events and that it caused fewer adverse events (13.7\% vs. $18.7 \%$ ) compared to ASA at a dose of $3000 \mathrm{mg} / \mathrm{d}$ (46).

Non-steroidal anti-inflammatory drugs are the group of drugs most commonly used in therapy, especially by the elderly population, but also for which particularly many complications, including severe ones, are reported. Studies show that their number of fatal side effects is greater than the number of deaths from e.g. myeloma, cervical cancer, or asthma. They are responsible for more than 100000 hospitalizations per year due to gastroenterological complications and over 20000 deaths per year. Although the adverse effects of NSAIDs on gastric and duodenal mucosa are known, often dyspeptic symptoms are neglected by patients. The greatest risk of gastrointestinal damage occurs during the first 30 days of intake, but cases of upper gastrointestinal bleeding have been reported following the first dose. Risk factors for severe gastrointestinal damage include elderly age (20-40\% of elderly people taking NSAIDs for 5-7 days suffer from gastrointestinal mucosal ulcers), high dose, simultaneous use of 2-3 drugs from this group, ulcer disease, Helicobacter pylori infections, history of gastrointestinal bleeding, male gender, smoking, alcohol abuse, concomitant intake of glucocorticosteroids, anticoagulants, and serotonin reuptake inhibitors (6, 47-49). Persons using acetylsalicylic acid (aspirin) in the prevention of heart attacks or ischemic strokes should not use preparations containing ibuprofen. By inhibiting uric acid excretion, ASA may be responsible for urate seizure. In $0.3 \%$ of the population, hypersensitivity in the form of aspirin-dependent asthma, rhinitis, chronic urticaria, or vascular edema is observed. To reduce the risk of side effects, it is recommended to take NSAIDs together 
with food, but it is important to remember that absorption is significantly slowed down and the analgesic effect occurs. The irritating effect reduces the amount of liquid that is drunk. In patients with risk factors of gastrointestinal damage, it is recommended to use drugs from the group of proton pump inhibitors (PPI), as well as selecting selective or preferential COX-2 inhibitors. Combining drugs from the group of NSAIDs and PPIs leads to the protection of the gastrointestinal mucosa, but due to the increased $\mathrm{pH}$ value, it may reduce the absorption of NSAIDs, which in turn may translate into a lower analgesic and anti-inflammatory effect. It is a mistake to use $\mathrm{H} 2$ blockers (ranitidine, famotidine) as a protective factor in patients taking NSAIDs, because they do not prevent the formation of ulcers, but mask symptoms of gastrointestinal damage (4, 4952). The contribution of isoenzyme CYP2C9 of cytochrome P450 to the metabolism of many drugs of this group, including ibuprofen and diclofenac, may cause undesirable pharmacokinetic interactions with drugs stimulating or inhibiting its activity. CYP2C9 inductors, responsible for faster elimination of drugs and problems in achieving therapeutic concentration, include valproic acid, phenobarbital, rifampicin. CYP2C9 inhibitors that increase the concentration of the drug and lead to adverse effects are amiodarone, fluconazole, fluoxetine, sertraline, fluvastatin, lovastatin. Due to the genetically determined polymorphism of $\mathrm{CYP} 2 \mathrm{C} 9$, an additional risk of complications is the membership in a population with reduced activity of this enzyme $(47,53,54)$.

A serious problem, which may be responsible for exceeding the acceptable dose and occurrence of undesirable effects, is the presence on the market of medicinal products with different trade names but containing the same active substance, e.g. ibuprofen is found in simple preparations such as Ibum, Ibalgin, Dolgit, Nurofen and as a component of complex preparations such as Acard sinus, Metafen, Modafen Extra Grip. The availability of paracetamol under various trade names in the form of many simple preparations such as Apap, Acenol, Codipar Solpadeine and complex preparations such as Apap Extra, Saridon, Fervex, Gripex, Theraflu is also dangerous. Their use by patients who do not read the drug leaflets and treat them as completely different drugs with different active substances threatens not only the health but also the lives of patients. In the case of paracetamol, it may be associated with the development of hepatotoxicity, for which its metabolite N-acetyl-p-benzoquinone imine (NAPQI), inactivated by coupling with glutathione, is responsible. An overdose of paracetamol causes depletion of hepatic glutathione and the toxic effects of NAPQI on hepatocytes. The risk group for liver damage includes patients with glutathione deficiency: alcoholics, diabetics, starving, malnourished and chronic use of anticonvulsants, cytochrome inducing P450 (barbiturates, carbamazepine, phenytoin, rifampicin), and cigarette smokers. Glutathione reserves in the liver also reduce the pyrrolizidine alkaloids of the coneflower (Echinacea). It is necessary to be careful when combining paracetamol, metabolized with isoenzyme CYP1A2, with drugs inhibiting its activity - ciprofloxacin, erythromycin, fluvoxamine, ticlopidine. The drug increases renal excretion of prostaglandins and reduces plasma renin activity, so it may reduce diuretic loop diuretics. Combined use with warfarin increases the risk of hemorrhagic complications and requires monitoring of the INR $(8,20,55)$. Paracetamol is a relatively safe drug, recommended as an effective drug in musculoskeletal, visceral, and soft tissue pain of various etiologies, well-tolerated, and of choice in patients with active gastric and duodenal ulcers, coagulation disorders who cannot take NSAIDs, moreover, in pregnant and breastfeeding women and in children due to the risk of Reye's syndrome associated with the use of salicylates. However, it is necessary to pay attention to its side effects and the frequency exceeding its permissible dose $(4 \mathrm{~g} / \mathrm{d})(6$, 55). In this study, allergic reactions, heartburn, reflux, and irritable bowel syndrome were observed in $6(9.5 \%)$ out of $63(16.9 \%)$ people combining paracetamol with another analgesic and in 2 out of 4 people taking it several times a month as monotherapy. The addition of NSAIDs to paracetamol is recommended in case of increased pain. The mechanism of analgesia is based on the blocking of COX1 and COX-2 in tissues and organs and the not fully understood the central action. However, the duration of the therapy should be as short as possible and the dose of drugs should be the lowest effective (6). A small number of reports (4) also came to the Regional Center for Monitoring Adverse Drug Actions in Wrocław. 28 of them were submitted to the MAH US Pharmacia, they concerned skin lesions, but also weakness, malaise, increase in blood pressure, impaired kidney function, and even muscle weakness in the limbs after taking $3000 \mathrm{mg}$ of the drug. There were 61440 reports in the EudraVigilance database during the analyzed period. Most of them were between 18 and 64 years old, mostly women. General disorders at the site of administration dominated (2189), although the authors' attention was drawn to a large number of skin reactions and subcutaneous tissue damage 
(1696), as well as disorders of the gastrointestinal tract (1505). In the light of the above information, special attention should be paid to the observations of Joslin et al., who found the common use of paracetamol in doses higher than recommended among runners (marathon runners and ultramarathon runners) during training, racing, and convalescence (56).

Metamizole, a prodrug, is used in the treatment of acute and chronic pain, headache, after surgery, locomotor system diseases, and neoplasms. Its additional advantage is the diastolic effect in spastic smooth muscles. Until August this year, the EudraVigilance database contained 10164 reported adverse effects of metamizole. As many as 4788 were observed in people aged 18-64, 5997 in women, 402 were skin reactions and subcutaneous tissue damage. However, the number of its side effects has recently increased. These included gastrointestinal disturbances, drops in blood pressure, headache, arrhythmias, bronchospasm, especially in people with asthma, and maculopapular rash. Most of them resolved after drug discontinuation. The most controversial complication is metamizoleinduced agranulocytosis, the first description of which dates back to 1936 . For this reason, in the 1960 s, it was withdrawn from the market or was never approved in many countries, including Australia, Canada, France, India, Japan, the Scandinavian countries, the United States, Great Britain. However, in some cases, it is available on prescription (e.g. Belgium, Germany, Italy, Portugal, Spain, and Switzerland) or without a prescription (e.g. Brazil, China, Israel, Mexico, Poland, Turkey, and Russia). Prolonged use of this medicine may cause hematopoietic dysfunction. Attention is paid to the genetically determined activity of mechanisms leading to neutropenia or agranulocytosis. Studies conducted by Basak et al. in Poland have shown its occurrence in 0.7 cases per million adult inhabitants of the country. The results of in vitro observations did not prove greater myelotoxicity of the drug in comparison with e.g. diclofenac or acetylsalicylic acid. Due to its contribution to the metabolism of metamizole isoenzymes CYP2B6, CYP2C8, CYP2C9, and CYP3A4, it may cause many undesirable interactions, and in patients with liver failure, its use is limited and requires caution. Most published clinical reports describe single cases of hepatotoxicity. It can be interpreted in the context of multi-organ failure caused by metamizole poisoning as a consequence of observed renal failure. It may also be caused by an allergic mechanism (14, 57-59).
Despite the possibility of adverse drug reactions being reported by the patient or their caregiver in 2013, there are still relatively few people using this right, unaware of the significant role they can play in the pharmacovigilance system. It is the patient who experiences a particular drug complication who can best characterize it. The information collected makes it possible to identify, among other things, groups of people who should avoid a given medicinal product or modify its dosage. It also makes it possible to identify risk factors for their occurrence. Most of the respondents in this study showed knowledge about the possibility of passing on data on adverse drug reactions. Out of 371 respondents who reported taking painkillers from the OTC group, 236 $(63.6 \%)$ stated that they knew who can report them. The doctor was indicated by $327(88.1 \%)$ respondents, the pharmacist by $306(82.5 \%)$, the patient and his guardian by $301(81.1 \%)$, the nurse by 277 $(72.7 \%)$, and the paramedic by $276(74.4 \%)$. Unfortunately, the observations confirmed that despite the knowledge of the monitoring of adverse drug reactions, only individual people do it.

The own study was also aimed at determining where non-opioid analgesics are purchased. 255 (96.5\%) of the respondents purchased them in a pharmacy, $132(35.6 \%)$ in a supermarket or store, 32 $(8.6 \%)$ in a drugstore, $21(5.6 \%)$ in a gas station. 185 $(49.9 \%)$ respondents stated they had bought them in non-pharmacy outlets. The observations of other authors do not inspire such optimism. Kozłowski et al. stated a much smaller percentage of respondents who use the purchase of these drugs in a pharmacy $(48,44.4 \%)$. The data on the purchase of painkillers in non-pharmacy points were similar (41). Observations in the Netherlands showed that both the general population $(58 \%)$ of patients and the gastric risk group (62\%) purchased NSAIDs of OTC availability mainly in drugstores (23\%), followed by pharmacies $(21 \%)$ and supermarkets $(15 \%)$. The difference concerned the place of obtaining information about the drug. People at risk of complications, first of all, used professional advice in a pharmacy $(88 \%)$, then in a drugstore $(50 \%)$, or supermarket (25\%). The general population received information in a drugstore (47\%), a pharmacy (33\%), and a supermarket (25\%) (42).

As stated, drug buyers in pharmacies did not always obtain information from the pharmacist about the medicinal product they bought. Only 175 $(41.7 \%)$ respondents received it. They mainly concerned the dosage, time of intake, and pre/post/after meal intake. Only $34(9.2 \%)$ respondents heard about possible side effects. Do pharmacists forget 
that an indispensable activity accompanying the release of a drug from a pharmacy, including a medicinal product of OTC availability category, is based on current knowledge advice? All over the world, apart from advanced pharmaceutical services, patients can count on it. Pharmacists belong to the medical profession and should also provide preventive services and participate together with the doctor in patient care $(60,61)$.

Our observations showed that $97.3 \%$ of the respondents were familiar with the content of the drug leaflets, but $78.4 \%$ stated they understood their content, and $37.1 \%$ only some of them. Is the cause only on the side of patients? The understanding of the contents of the package leaflets is also influenced by their formal criteria, such as readability and layout, which unfortunately leave much to be desired. The current leaflets are primarily legal forms, and although Article 56 of the European Commission's Directive 2001/83/EC requires them to be "easily legible" and "understandable", they are often difficult to treat as a patient-friendly information tool, even for professional medical personnel. Research carried out by the Dutch Institute for Health Services Research (NIVEL) and the University of Leeds has shown that it is possible to improve patient understanding and readability of the leaflets. The language used is often too complex and the design and layout are not always convenient for the user. Especially the elderly and those with low literacy skills are at a disadvantage. Research has shown that difficulties, e.g. in interpreting a large number of adverse effects in the leaflets also affect professional staff health care $(62,63)$. This is a particular problem, as $89 \%$ of Poles buy OTC drugs, $70 \%$ of which are painkillers (64). $92.2 \%$ of the respondents followed the leaflet's recommendations, $36.9 \%$ admitted that they sometimes skip the dose of the drug, $21.8 \%$ increased it when they felt the drug was not working enough, $31.3 \%$ decreased it when they did not feel pain and $34.8 \%$ interrupted the therapy. As the main source of information about drugs, $80.1 \%$ of respondents indicated the leaflet, $64.4 \%$ the Internet, $58.8 \%$ a doctor, and only $47.2 \%$ a pharmacist. These observations do not inspire optimism. Not fully understanding the contents of the leaflets and still too rarely obtaining full information from pharmacists about the painkillers they buy may be dangerous as a consequence. Also, there are no restrictions in Poland regarding maximum quantities or doses of drugs sold in facilities other than a pharmacy, which applies especially to nonsteroidal inflammatory drugs and paracetamol (65). In one study, 20 out of 275 people taking OTC painkillers incompetently were found to need even a liver transplant (66). As shown by CBOS studies, $22 \%$ of people, especially those aged 18-24 years, are not worried about the negative health effects of OTC drugs, $41 \%$ of them questioning possible side effects. 52\% consult the use of new OTC drugs with their doctor or pharmacist, $28 \%$ do so each time they use an unknown preparation. $88 \%$ of people $(69 \%$ always) read the prescription leaflet and $29 \%(7 \%$ always) check the information on the Internet. $28 \%$ have taken OTC drugs in the wrong way - contrary to the recommendations, e.g. increasing the dose, using them longer than indicated (20\%), disregarding side effects $(9 \%)$ or contraindications that concern them (8\%), as well as taking drugs out of habit, although it is not necessary (7\%), and contrary to the negative opinion of the doctor about such treatment (4\%) (39). Szpringer et al. demonstrated in a study conducted in 114 people living in rural areas of the Świętokrzyskie province that women took OTC drugs from advertisements $(47.62 \%)$ and their families $(36.51 \%)$ and men from advertisements $(37.25 \%)$ and a pharmacist (35.29\%). Men, statistically significantly more often than women, searched for information on the Internet $(p=0.0477)$. The respondents declared that it was the pharmacist's duty to inform about adverse drug reactions, and, what is interesting, none of the women stated that they may not do so (66).

To sum up, it should be stated that the most commonly used over-the-counter painkillers are: ibuprofen, acetylsalicylic acid, and paracetamol and combinations of ibuprofen with paracetamol, as well as the non-recommended ibuprofen with acetylsalicylic acid. Complications of ibuprofen pharmacotherapy including skin reactions and subcutaneous tissue damage, gastrointestinal disorders, and general disorders with swelling were most common in people aged 18-64, more often in women than men. Complications after the use of ASA concerned the gastrointestinal and nervous systems, and general disorders at the site of administration, and were observed especially in persons aged 18-64 years, more often in men than in women. As a result of paracetamol application, skin reactions, subcutaneous tissue damage, general abnormalities, and reactions at the site of administration were observed. In increasing the safety of an analgesic treatment, the importance of pharmacists providing reliable and objective information on medicinal products cannot be overstated. Their competence as highly qualified people should be reflected in such activities, as only full knowledge of the drug will allow them to protect patients from the negative conse- 
quences of improperly taking painkillers or seeking help from so-called "healers". It is very important to observe the principles of rational use. One of them concerns the monitoring of the undesirable effects of drugs. Any information of an individual nature concerning side effects increases the safety of the use of a given medicine on a global level and allows one to determine the benefits in terms of risk for the patient. In this way, the knowledge about the drug is supplemented and expanded, and later reaches the doctor and the patient in the form of new or supplemented information about the drug contained in the summary of product characteristics and leaflet. This enables one to make an informed choice about the best medicinal product. All of us who use medicines should be aware that reporting side effects not only help us but also protects others.

This research was funded by Wroclaw Medical University, grant no ST.SUB.D200.19.037

\section{Conflict of interest}

The authors declare no conflict of interest.

\section{REFERENCES}

1. International Association for the study of Pain, IASP Terminology, https://www.iasp-pain.org/ terminology (accessed on 21.09.2020).

2. Wordliczek J., Zajączkowska R., Woroń J., Misiołek H., Malec-Milewska M.: Anest. Ratow. 14, 89 (2020).

3. Zimmermann A., Mędrzycka-Dąbrowska W., Zagłoba M.: Palliat. Med. Pract. 12, 21 (2018).

4. Leppert W., Wordliczek J. Eds.: Oncol. Clin. Pract. 14, 1 (2018).

5. Wehling M.: Eur. J. Clin. Pharmacol. 70, 1159 (2014).

6. Kotlińska-Lemieszek A.: Med. Prakt. 11, 110 (2019).

7. Ingrasciotta Y., Sultana J., Giorgaianni F., Menditto E., Scuteri A., et al.: PLos One 14, e0222836 (2019).

8. Neumann-Podczaska A., Nowak T., Wieczorowska-Tobis K.: Gerontol. Pol. 4, 133 (2013) (in Polish).

9. Moore A., Crossley A., Ng B., Phillips L., Sancak Ö., Rainsford K.D.: J. Pharm. Pharmacol. 69, 1364 (2017).

10. Yousefifard M., Askarian-Amiri S., Neishaboori A.M., Sadeghi M., Saberian P., Baratloo A.: Arch. Acad. Emerg. Mede. 7, e55 (2019).

11. Moore N., Scheiman J.M.: Postgrad. Med. 130, 188 (2018).
12. Mulka-Gierek M., Foroncewicz B., Pączek L., Wawiórko E., Kamińska J., et al.: Ann. Transplant. 23, 153 (2018).

13. Misiołek H., Zajączkowska R., Daszkiewicz A., Woroń J., Dobrogowski J., et al.: Anest. Intens. Ter. 50, 175 (2018).

14. Jasiecka A., Maślanka T., Jaroszewski J.J.: Pol. J. Vet. Scien. 17, 207 (2014).

15. Rotundo L., Pyrsopoulos N.: World J. Hepatol. 12, 125 (2020).

16. Szałek E.: Farm. Wsp. 11, 127 (2018).

17. Samborski W., Sikorska D., Niklas A., Filipiak K.J., Kaczmarczyk J., et al.: Forum Reumatol. 4, 143 (2018).

18. Krzyżak-Jankowicz M., Jankowicz R.: Med. Paliat. Prakt. 9, 59 (2015).

19. Khan S., Andrews K.L., Chin-Dusting J.P.F.: Int. J. Mol. Sci. 20, 4262 (2019).

20. Ishitsuka Y., Kondo Y., Kadowaki D.: Biol. Pharm. Bull.43, 195 (2020).

21. Hoffmann F., Bantel C., Jobski K.: Basic Clin. Pharmacol. Toxicol. 126, 116 (2020).

22. Schneider J., Kreutz R., Bolbrinker J.: Schmerz 33, 165 (2019).

23. Dreiver B., Marks D.C., van der Wal D.E.: Res. Pract. Thromb. Haemost. 4, 36 (2020).

24. Broniarczyk-Dyła G., Urysiak-Czubatka I.: Post. Dermatol. Alergol. XXIV, 274 (2007).

25. Kowalski M.L., Stevenson D.D.: Immunol. Allergy Clin. North Am. 33, 135 (2013).

26. Rahman S., Malcoun A.: Prim. Care. 41, 803 (2014).

27. Gunter B.R., Butler K.A., Wallace R.L., Smith S.M., Harirforoosh S.: J. Clin. Pharm. Therap. 42, 27 (2017).

28. Bakhriansyah M., Souverein P.C., de Boer A., Klungel O.H.: J. Clin. Pharm. Ther.44, 623 (2019).

29. White P.F.: Expert Opin. Pharmacother. 18, 329 (2017).

30. Vuik F.E.R., Koehestanie P., Herbers A.H.E., Doroste J.S.T.S.: Neth. J. Med. 75, 81 (2017).

31. Modig S., Elmstahl S.: Int. J. Clin. Pharm. 40, 870 (2018).

32. Wolska A., Wolska J., Kowalczyk E., Wiktorowska-Owczarek A.: Farm. Pol. 74, 295 (2018).

33. Roshi D., Toci E., Burazeri G., Scroder-Back P., Malaj L., Brand H.: Mater. Sociomed. 29, 138 (2017).

34. Reist L., Erlenwein J., Meissner W., Stammschulte T., Stuber F., Stamer U.M.: Eur. J. Pain 22, 1103 (2018).

35. Govender T., Brand M.: S. Afr. Pharm. J. 85, 65 (2018). 
36. Rell K.: Forum Med. Rodz. 8, 292 (2014).

37. Jóźwiak-Bębenista M., Nowak J.: Acta Pol. Pharm. 71, 11 (2014).

38. White W.B., Kloner R.A., Angiolillo D.J., Davidson M.H.: J. Cardiovasc. Pharmacol. Therap. 23, 103 (2018).

39. Feliksiak M.: Komunikat $\mathrm{z}$ badań CBOS Centrum Badania Opinii Społecznej 158, 1-16 (2016).

40. Synoweć J., Pogorzelczyk K., Robakowska M., Ślęzak D., Żuratyński P., et al.: Med. Rodz. 3, 281 (2018).

41. Kozłowski P., Cuch B., Kozłowska M., Kozłowska K., Jędrzejewska B.: J. Educ. Health Sport 5, 174 (2015).

42. Koffeman A.R., Valkhoff V.E., Celik S., Jong G.W., Sturkenboom M.C.J.M., et al.: Brit. J. Gen. Pract. 191 (2014).

43. Reguła J., Wocial T., Kraszewska., Butruk E.: Gastroenterol. Klin. 3, 72 (2011).

44. Varassi G., Pergolizzi J.V., Dowling P., Paladini A.: Adv. Ther. 37, 61 (2020).

45. Drożdżal S., Rosik J., Lechowicz K., Machaj F., Szostak B., et al.: Brain Sci. 10, 465, (2020).

46. Moore N., Pollack C., Butkerait P.: Therap. Clin. Risk Manag. 11, 1061 (2015).

47. Theken K.N., Lee C.R., Gong L., Caudle K.E., Formea C.M., et al.: Clin. Pharmacol. Therap.191 (2020).

48. Heleniak Z., Cieplińska M., Szychliński T., Rychter D., Jagodzińska K., et al.: J. Nephrol. 30, 781 (2017).

49. Zaremba M., Staniszewska A., Niewada M.: Chor. Serc. Nacz. 9, 119 (2012).

50. Szymański F.M., Filipiak K.J., Krasiński Z., Reguła J., Małecki M., Sławek J.: Chor. Serc. Nacz. 13, 147 (2016).
51. Broncel M.: Geriatria 13, 50 (2019) (in Polish).

52. Woroń J., Wordliczek J., Dobrogowski J.: Med. Dypl. 20, 55 (2011) (in Polish).

53. Krasniqi V., Dimovski A., Domjanovic I.K., Bilić I., Bozina N.: Arh. Hig. Rada Toksikol. 67, 1 (2016).

54. Czuba E., Klimowicz A., Bielecka-Grzela S., Kacalak-Rzepka A.: Post. Dermatol. Alergol. 26, 529 (2009).

55. Słaby M., Szczukocka M., Pulkowski M., Słaby D., Beberok A., Wrześniok D.: Farm. Pol. 75, 389 (2019) (in Polish).

56. Joslin J., Lloyd J.B., Kotlyar T., Wojcik S.M.: S. Afr. J. Sport Med. 25, 101 (2013).

57. Lutz M.: J. Clin. Pharmacol. 59, 1433 (2019).

58. Krzych Ł.J.: Anest. Ratow. 5, 473 (2011) (in Polish).

59. Drobnik L.: Anest. Ratow. 4, 40 (2010) (in Polish).

60. Świeczkowski D., Merks P., Jaguszewski M.: Farm. Pol. 72, 286 (2016) (in Polish).

61. Zimmermann A., Adrych-Brzezińska I.: Farm. Pol. 73, 692 (2017) (in Polish).

62. Muhlbauer V., Prinz R., Muhlhauser I., Wegwarth O.: PLos One 13, e0203800 (2018).

63. Mühlbauer V., Mühlhauser I.: BMC Health Serv. Res. 15, 505 (2015).

64. Bułaś L., Hansel J., Wajda A., Dolińska B., Drozd M.: Act. Pol. Pharm.76, 1099 (2019).

65. Raport Pozaapteczny obrót lekami OTC. Bezpieczeństwo, ekonomia i oczekiwania pacjentów. Stowarzyszenie Leki Tylko z Apteki. (2018) (in Polish).

66. Szpringer M., Olędzka M., Kosecka J., Galińska E.M., Chmielewski J., et al.: Med. Og. Nauk Zdr. 21, 158 (2015) (in Polish).

(c) 2020 by Polish Pharmaceutical Society. This is an access article under the CC BY NC license (http://creativecommons.org/licenses/by-nc/4.0/). 